\title{
Risk for depression : a 6-year follow-up of Finnish adolescents
}

\section{Pelkonen, Mirjami}

2003-10

Pelkonen , M , Marttunen , M \& Aro , H 2003 , ' Risk for depression : a 6-year follow-up of

Finnish adolescents ' , Journal of Affective Disorders, vol. 77 , no. 1 , pp. 41-51 . https://doi.org/10.1016/S0165-0327

http://hdl.handle.net/10138/297744

https://doi.org/10.1016/S0165-0327(02)00098-8

publishedVersion

Downloaded from Helda, University of Helsinki institutional repository.

This is an electronic reprint of the original article.

This reprint may differ from the original in pagination and typographic detail.

Please cite the original version. 


\title{
Risk for depression: a 6-year follow-up of Finnish adolescents
}

\author{
Mirjami Pelkonen, Ph.D. ${ }^{\text {a,b,* }}$, Mauri Marttunen, M.D., Ph.D. ${ }^{\text {a,b }}$, \\ Hillevi Aro, M.D., Ph.D. ${ }^{\text {a }}$ \\ ${ }^{a}$ Department of Mental Health and Alcohol Research, National Public Health Institute, Mannerheimintie 166, FIN-00300 Helsinki, Finland \\ ${ }^{\mathrm{b}}$ Department of Adolescent Psychiatry, Hospital District of Helsinki and Uusimaa, Peijas Hospital, Vantaa, Finland
}

Received 22 December 2000; received in revised form 25 March 2002; accepted 26 March 2002

\begin{abstract}
Background: Few longitudinal studies have attempted to identify risk factors in mid-adolescence for subsequent depression in young adulthood. Mid-adolescence is a critical developmental phase for studying vulnerability to depression due to high incidence and prevalence of depression. Methods: In a longitudinal study, following an urban Finnish community cohort (761 males and 887 females) from age 16, mid-adolescent risk factors for depression at age 22 years were studied. Data were collected by a questionnaire at school at age 16 , and by a postal questionnaire at age 22 . Results: Of the females $116(13 \%)$ and of the males $69(9 \%)$ had depression (S-BDI) in young adulthood. In multivariate analyses baseline depressive symptoms, low self-esteem, dissatisfaction with academic achievement, problems with the law, poor atmosphere at home and having no close friends predicted subsequent depression. Risk factors for males included more 'externalizing' aspects, for females more 'internalizing' factors. Conclusions: Mid-adolescence is an important age to study risk for depression, and self-reported perceptions of psychosocial well-being have predictive value. Preventive efforts can be selectively targeted at adolescents who have been exposed to identifiable risk factors.
\end{abstract}

(c) 2002 Elsevier B.V. All rights reserved.

Keywords: Adolescence; Depression; Longitudinal study; Risk factors

\section{Introduction}

Results from longitudinal community studies suggest that mid-adolescence is a critical developmental phase for studying vulnerability to depression due to its high incidence and prevalence, particularly among females, resulting in a marked female preponderance of depression (Hankin et al., 1998).

\footnotetext{
*Corresponding author. Tel.: +358-9-47448213; fax: +358-947448478.

E-mail address: mirjami.pelkonen@ktl.fi (M. Pelkonen).
}

Adolescence is a period of major biological, psychological and social developmental changes. Of special interest are the links or lack of links between normal emotions or behavior and clinical disorders or illness. Similarly, there is a focus on the parallels or lack of parallels between 'normal' processes of adaptation and change and 'abnormal' responses to stress or adversity. During adolescence, new awareness and expanding options of alternatives in relation to school, vocational training and individual relationships may contribute to mature modes of development, or conversely, to identity problems (Sugar, 1992). 
Depression is twice as common in adolescence as in childhood (McGee et al., 1992), and is associated with severe psychosocial impairment and subsequent morbidity (Puig-Antich et al., 1993; Birmaher et al., 1996). Several developmental pathways for depression during adolescence appear plausible. Depression might result from a series of events and processes, including genetic susceptibility, biological insults, temperament, and other individual characteristics such as low self-esteem (Renouf and Harter, 1990), environmental events, developmental changes, and available coping responses (Petersen et al., 1993). Biological changes might serve to heighten or maintain the psychological distress experienced by a depressed individual. In addition, chronic or extreme stresses, e.g. those associated with parental divorce (Aro and Palosaari, 1992), parental indifference, and sexual and physical abuse (Brown and Harris, 1993) constitute risk factors for depression (Petersen et al., 1993).

Abundant research has examined psychosocial correlates of depression, though fewer studies have attempted to elucidate its risk factors. Clarifying risk factors for depression is critical both for developing and evaluating theories of the etiology of depression and for identifying individuals at elevated risk for developing this disorder (Lewinsohn et al., 1999).

Further longitudinal epidemiological research is clearly needed to discover whether depression in adolescence is associated with normative adolescent developmental or whether it is a psychiatric disorder with subsequent psychiatric morbidity and impairment (Rutter, 1989; Aro, 1994; Champion et al., 1995).

In previous research, depression in adolescent females has reportedly been associated with uncontrollable events (Ge et al., 1994), negative self-esteem, and negative body image (Allgood-Merten et al., 1990). Among adolescent males, early childhood poor health and developmental problems predicted major depression (Reinherz et al., 1999), and conduct problems increased risk for subsequent depressive symptoms (Capaldi and Stoolmiller, 1999). For both genders, depressive symptoms predict subsequent depression regardless of the method of its assessment (Lewinsohn et al., 1995; Frost et al., 1999).

Using data from a community-based 6-year longitudinal study and within the limitations of question- naire data (Aro, 1994), the aim of this study was to examine risk factors for depression. We examined whether perceptions of well-being, personal characteristics, problem behavior and interpersonal problems were risk factors for depression in young adulthood. We expected symptoms of depression in mid-adolescence to be risk factors for depression in young adulthood for both genders. Further, we expected low self-esteem to be a risk factor for females and problems with the law for males.

\section{Method}

\subsection{Subjects and measures}

The subjects of this study included all 9th grade students attending secondary schools in Tampere, a Finnish city of 166000 inhabitants, in the spring of 1983 (Aro, 1994). Of a total of 2269 pupils, 96.7\% $(N=2194)$ participated in the study and completed questionnaires in the classroom. Their mean age was 15.9 years (S.D. $=0.3$ years). The same young people were re-examined using postal questionnaires in spring 1989 at the age of 22 years. Of the original population, four persons had died, 18 could not be identified due to inappropriate completion or missing identification numbers, and 33 persons could not be traced. Thus, the follow-up cohort included 2139 persons, and the participation rate was $77.4 \%$ $(N=1656)$.

\subsubsection{First phase}

Baseline data collected in self-reported questionnaires at 16 years included a checklist of distress symptoms, and questions about personal characteristics, behavior, and life situation (e.g. family background) (Aro, 1987). At baseline no standard measure of depression was used. However, the series of 17 distress symptoms, each assessed on a four-point scale (Aro and Rantanen, 1992) included seven items indicative of depression: lack of energy, sleeping difficulties, nightmares, fatigue, irritability, loss of appetite, and nervousness/anxiety, four of which are used as symptoms of clinical depression, e.g. in the DSM-IV-classification (American Psychiatric Association, 1994). A sum score of these items was used as a measure of symptoms of depression, the theoretical 
range of which was $0-21$. The internal reliability of the scale was 0.69 among the females and 0.75 among the males by Cronbach's alpha.

Self-esteem was measured using a seven-item, five-point scale developed for Finnish students (Aro, 1988). The adolescents assessed their health status on a five-point scale, and the statements were dichotomized (very/rather good; average/rather/very poor). A semantic differential scale of individuation was created. The statements regarding relationship with and independence from parents yielded three factors in the factor analyses, interpreted as: individuation, relationship with mother and relationship with father. The scale of individuation consisted of four self-assertions rated on a five-point scale, and the theoretical range was 4-20. The items were: 'My parents trust me', 'My parents let me make my own decisions', 'I often feel that I disappoint my parents' expectations' and 'I feel that my parents are disappointed with my academic achievement'. The internal reliability of the scale of individuation was 0.71 among the females and 0.62 among the males. The semantic differential scale of future orientation used consisted of two selfassertions rated on a five-point scale, and the theoretical range of the scale was $2-10$. The items were: 'I have clear plans for the future', and 'I am uncertain about the future'. The internal reliability of this scale was 0.72 among the females and 0.73 among the males by Cronbach's alpha.

Self-reported means of school marks (min. 4, max. 10) were used as a measure of academic achievement. Satisfaction with academic achievement was assessed on a five-point scale, which was dichotomized (very/ rather satisfied; average/rather/very dissatisfied). Adolescents who reported that they had dated, for however short a period, were included in the group with dating experiences. Those who reported using alcohol at least monthly and being intoxicated by alcohol at least four times during the term were included in the excess drinking group. Adolescents who reported breaking the law with consequences during the last 12 months were classified as having problems with the law. Relationships with teachers and peers were reported on separate four-point scales, both dichotomized (good relationships with most/rather many; with some/none). The students also reported on a four-point scale the number of close friends ( 0 to more than five) and the scale was dichotomized: no friends; one/more friends. The life event scale was constructed on the basis of previous life event lists of young people over 12 months, and the scores of independent events and interpersonal problems were constructed (Aro, 1987).

The subjects were grouped into three classes based on a standard classification of occupations (Central Statistical Office of Finland, 1975) using primarily the father's occupation, but if missing, the mother's. In cases of unknown occupation the assignment of social class was based on the parent's occupation. Relationships with mother and father were measured using five-point scales (Aro et al., 1989). In addition, a statement on atmosphere at home (Tulisalo and Aro, 2000) was used.

\subsubsection{Second phase}

Depression at 22 years was used as the outcome measure. It was assessed by the short, 13-item version of the Beck Depression Inventory (Beck and Beck, 1972; Beck et al., 1974), validated in Finnish population studies by including introductory questions and an additional positive choice of answer for each item (S-BDI) (Kaltiala-Heino et al., 1999); the latter did not affect the scoring of depression. The theoretical range of the scale was $0-39$. The subjects with S-BDI points $0-4$ were classified as having no depression, those with 5 or more as having depression (Beck and Beck, 1972; Aro, 1994). Due to missing data on depression scores in five males and three females, the number of male subjects totalled 761 and that of female subjects 887 in the analyses.

The comparison of participants and non-participants at follow-up showed that at baseline the latter were more often males, and that they did poorly at school. No statistically significant differences were found in parental divorce, parental socioeconomic status or in the symptom scores at 16 years.

\subsection{Statistical methods}

According to depression at follow-up, two groups were used: S-BDI points $0-4$ defines those with no depression, and a score of 5 or more was taken to indicate the presence of depression. Differences between groups at baseline were analyzed using the $\chi^{2}$ test and Student's two-tailed $t$-test when appropriate. The sum scores of the variables concerning state- 
ments/symptoms at baseline were dichotomized using the median as the cut-off point. The two-way interactions by sex for each predictor variable were calculated in univariate logistic regressions. Multivariate logistic regression analyses using backward stepwise procedure were used to select variables associated with the dependent variable. In the multivariate analyses, $P$-values $<0.01$ were considered statistically significant. The fit of the model was measured by the Hosmer and Lemeshow goodnessof-fit $\chi^{2}$-test.

\section{Results}

\subsection{Males}

Of the males, 69 (9.1\% of 761) had depression at age 22 years; the mean of the depression score (S-
BDI) was 1.4, median 0, S.D. 2.8, and range 0-24. At baseline, the mean score of symptoms of depression was 3.4, median 3.0, S.D. 2.6, range $0-16$. There were no statistically significant differences at baseline between the males with depression (S-BDI) and those with no depression (S-BDI) at age 22 years in age (mean 15.9 years in both groups) or in parental SES (Table 1).

High symptom score of depression, low self-esteem, low sense of individuation, poor perceived health status, and dissatisfaction with own academic achievement at baseline associated with later depression. At baseline, the mean of school marks was lower among those with subsequent depression compared with those with no subsequent depression. Those with later depression were more often uncertain about the future (Table 1).

Among the males, problems with the law, having no friends, and poor relationships with peers associ-

Table 1

Individual and familial characteristics at age 16 years by depression (S-BDI) at age 22 years among the males $(N=761)$

\begin{tabular}{|c|c|c|c|c|c|c|c|c|}
\hline \multirow[b]{2}{*}{ Symptoms of depression ${ }^{\mathrm{a}}$ mean, S.D. } & \multicolumn{2}{|c|}{$\begin{array}{l}\text { No depression } \\
\text { S-BDI, } 0-4 \\
(N=692)\end{array}$} & \multicolumn{2}{|c|}{$\begin{array}{l}\text { With depression } \\
\text { S-BDI, } \geq 5 \\
(N=69)\end{array}$} & \multicolumn{2}{|c|}{$\begin{array}{l}\text { Total } \\
(N=761)\end{array}$} & $P$-value & $N$ \\
\hline & 3.2 & 2.5 & 5.5 & 2.9 & 3.4 & 2.6 & $<0.001$ & 758 \\
\hline Low self-esteem ${ }^{\mathrm{a}}$ mean, S.D. & 15.1 & 4.3 & 17.3 & 5.5 & 15.3 & 4.5 & $<0.001$ & 754 \\
\hline Low sense of individuation ${ }^{\mathrm{a}}$ mean, S.D. & 9.5 & 3.0 & 11.7 & 3.9 & 9.7 & 3.1 & $<0.001$ & 758 \\
\hline Poor perceived health $\%(N)$ & 10.3 & $(71)$ & 20.9 & (14) & 11.4 & $(85)$ & 0.010 & 748 \\
\hline Mean of school marks ${ }^{\mathrm{b}}$ mean, S.D. & 7.5 & 9.4 & 7.2 & 8.9 & 7.5 & 9.4 & 0.007 & 749 \\
\hline $\begin{array}{l}\text { Dissatisfied with academic } \\
\text { achievement } \%(N)\end{array}$ & 37.5 & $(260)$ & 50.7 & $(35)$ & 38.9 & $(295)$ & 0.033 & 760 \\
\hline Uncertain about future $\%(N)$ & 49.6 & $(340)$ & 62.3 & (43) & 50.8 & $(383)$ & 0.045 & 754 \\
\hline Excessive alcohol use \% $(N)$ & 21.4 & (148) & 21.7 & $(15)$ & 21.6 & $(163)$ & 0.975 & 755 \\
\hline Problems with the law $\%(N)$ & 6.1 & $(42)$ & 19.1 & (13) & 7.3 & $(55)$ & $<0.001$ & 751 \\
\hline Poor relationships with teachers $\%(N)$ & 11.3 & (78) & 17.4 & (12) & 11.8 & (90) & 0.133 & 761 \\
\hline Poor relationships with peers $\%(N)$ & 4.5 & (31) & 11.6 & (8) & 5.1 & (39) & 0.011 & 760 \\
\hline No close friends $\%(N)$ & 2.6 & (18) & 11.6 & (8) & 3.4 & $(26)$ & $<0.0001$ & 757 \\
\hline Not dating $\%(N)$ & 54.2 & $(375)$ & 60.9 & $(42)$ & 55.1 & $(417)$ & 0.311 & 757 \\
\hline Interpersonal problems $\%(N)$ & 38.1 & $(260)$ & 54.4 & (37) & 39.5 & (297) & 0.009 & 751 \\
\hline Life events $\%(N)$ & 44.7 & $(305)$ & 54.4 & (37) & 45.5 & $(342)$ & 0.123 & 751 \\
\hline Poor atmosphere at home $\%,(N)$ & 51.8 & $(355)$ & 78.3 & (54) & 54.2 & $(409)$ & $<0.0001$ & 754 \\
\hline Poor relationship with mother $\%,(N)$ & 50.7 & $(344)$ & 68.8 & (44) & 52.2 & $(388)$ & 0.006 & 743 \\
\hline Poor relationship with father $\%,(N)$ & 53.1 & (349) & 65.6 & $(42)$ & 54.2 & $(391)$ & 0.055 & 721 \\
\hline Parental divorce $\%,(N)$ & 20.1 & $(139)$ & 31.9 & $(22)$ & 21.4 & $(161)$ & 0.026 & 752 \\
\hline Parental SES, upper middle class $\%,(N)$ & 21.0 & $(145)$ & 20.6 & (14) & 21.0 & (159) & 0.441 & 758 \\
\hline lower middle class & 31.8 & $(220)$ & 25.0 & (17) & 31.3 & $(237)$ & & \\
\hline working class & 47.0 & $(325)$ & 54.4 & (37) & 47.8 & $(362)$ & & \\
\hline
\end{tabular}

\footnotetext{
${ }^{\mathrm{a}}$ Higher score $=$ poorer estimate.

${ }^{\mathrm{b}}$ Lower score $=$ poorer estimate.
} 
ated with later depression. Those with depression at 22 years had more interpersonal problems than those with no depression, and more commonly had a poor relationship with their mother. Those with subsequent depression more often than those with no depression reported poor atmosphere at home and had parental divorce at baseline (Table 1).

At baseline, $26.9 \%$ of the males with subsequent depression and $18.9 \%$ of those without reported not wanting to discuss their problems with anyone (Table 3). About one-third of the former had reported their personal problems only to age-mates, not to adults; only one had turned to a professional as an adolescent.

\subsection{Females}

Of the females $116(13.1 \%$ of 887$)$ had depression at age 22. The mean of the depression score (S-BDI) was 1.9 , median 0, S.D. 3.2, and range $0-39$. At baseline, age 16, the mean score of symptoms of depression was 4.5 , median 4.0, S.D. 2.7, range $0-$ 17. There were no statistically significant differences at baseline in the mean ages of the groups with or without depression (15.9 years in both groups) or in parental SES (Table 2).

High symptom score of depression, low self-esteem, low sense of individuation and dissatisfaction with own academic achievement at baseline associated with later depression. There were no statistically significant differences at baseline in the means of school marks. The females with depression at age 22 were more often uncertain about the future.

In addition, they were more likely than those with no depression to have poor relationships with teachers, and were less often dating. Those with later depression had more interpersonal problems at baseline as well as more independent life events. Poor

Table 2

Individual and familial characteristics at age 16 years by depression (S-BDI) at age 22 years among the females $(N=887)$

\begin{tabular}{|c|c|c|c|c|c|c|c|c|}
\hline \multirow[b]{2}{*}{ Symptoms of depression $^{\mathrm{a}}$ mean, S.D. } & \multicolumn{2}{|c|}{$\begin{array}{l}\text { No depression } \\
\text { S-BDI, } 0-4 \\
(N=771)\end{array}$} & \multicolumn{2}{|c|}{$\begin{array}{l}\text { With depression } \\
\text { S-BDI, } \geq 5 \\
(N=116)\end{array}$} & \multicolumn{2}{|c|}{$\begin{array}{l}\text { Total } \\
(N=887)\end{array}$} & $P$-value & $N$ \\
\hline & 4.4 & 2.6 & 5.7 & 3.1 & 4.5 & 2.7 & $<0.001$ & 887 \\
\hline Low self-esteem ${ }^{\mathrm{a}}$ mean, S.D. & 17.3 & 4.4 & 20.4 & 5.1 & 17.7 & 4.6 & $<0.001$ & 885 \\
\hline Low sense of individuation ${ }^{\mathrm{a}}$ mean, S.D. & 9.1 & 3.3 & 10.5 & 3.9 & 9.3 & 3.4 & $<0.001$ & 887 \\
\hline Poor perceived health $\%,(N)$ & 11.8 & $(90)$ & 13.9 & (16) & 12.0 & $(106)$ & 0.509 & 880 \\
\hline Mean of school marks ${ }^{\mathrm{b}}$ mean, S.D. & 7.8 & 8.8 & 7.7 & 9.1 & 7.8 & 8.8 & 0.210 & 873 \\
\hline $\begin{array}{l}\text { Dissatisfied with academic } \\
\text { achievement } \%,(N)\end{array}$ & 35.8 & $(276)$ & 54.3 & (63) & 38.3 & $(339)$ & $<0.0001$ & 886 \\
\hline Uncertain about future $\%,(N)$ & 62.8 & $(483)$ & 75.0 & (87) & 64.4 & $(570)$ & 0.011 & 885 \\
\hline Excessive alcohol use $\%,(N)$ & 19.5 & (149) & 19.3 & $(22)$ & 19.4 & $(171)$ & 0.969 & 880 \\
\hline Problems with the law $\%,(N)$ & 1.8 & (14) & 3.4 & (4) & 2.0 & (18) & 0.246 & 886 \\
\hline Poor relationships with teachers $\%,(N)$ & 7.5 & $(58)$ & 12.9 & $(15)$ & 8.2 & (73) & 0.048 & 887 \\
\hline Poor relationships with peers $\%,(N)$ & 6.0 & (46) & 10.3 & (12) & 6.5 & (58) & 0.075 & 887 \\
\hline No close friends $\%,(N)$ & 1.3 & $(10)$ & 2.6 & (3) & 1.5 & $(13)$ & 0.283 & 885 \\
\hline Not dating $\%,(N)$ & 43.1 & $(332)$ & 53.4 & $(62)$ & 44.4 & $(394)$ & 0.036 & 887 \\
\hline Interpersonal problems $\%,(N)$ & 50.4 & $(388)$ & 58.6 & $(68)$ & 51.5 & $(456)$ & 0.098 & 886 \\
\hline Life events $\%,(N)$ & 51.7 & (398) & 60.3 & (70) & 52.8 & $(468)$ & 0.082 & 886 \\
\hline Poor atmosphere at home $\%,(N)$ & 58.6 & $(450)$ & 72.2 & $(83)$ & 60.4 & (533) & 0.005 & 883 \\
\hline Poor relationship with mother $\%,(N)$ & 52.3 & $(401)$ & 62.6 & $(72)$ & 53.7 & $(473)$ & 0.040 & 881 \\
\hline Poor relationship with father $\%,(N)$ & 61.9 & $(464)$ & 71.8 & (79) & 63.1 & (543) & 0.043 & 860 \\
\hline Parental divorce $\%,(N)$ & 23.7 & $(182)$ & 33.3 & $(38)$ & 24.9 & $(220)$ & 0.027 & 882 \\
\hline Parental SES, upper middle class $\%,(N)$ & 19.5 & $(150)$ & 12.2 & (14) & 18.6 & $(164)$ & 0.102 & 883 \\
\hline lower middle class & 31.1 & (239) & 29.6 & (34) & 30.9 & (273) & & \\
\hline working class & 49.3 & $(379)$ & 58.3 & $(67)$ & 50.5 & $(446)$ & & \\
\hline
\end{tabular}

\footnotetext{
${ }^{\mathrm{a}}$ Higher score $=$ poorer estimate.

${ }^{\mathrm{b}}$ Lower score $=$ poorer estimate.
} 
Table 3

To whom do adolescents turn with personal problems in mid-adolescence by depression at age 22 years (S-BDI)

\begin{tabular}{|c|c|c|c|c|c|c|c|c|}
\hline & \multicolumn{4}{|c|}{ Females $(N=887)^{\mathrm{a}}$} & \multicolumn{4}{|c|}{ Males $(N=761)^{\mathrm{b}}$} \\
\hline & \multirow{2}{*}{\multicolumn{2}{|c|}{$\begin{array}{l}\text { No depression } \\
(N=770) \\
\text { S-BDI, } 0-4\end{array}$}} & \multirow{2}{*}{\multicolumn{2}{|c|}{$\begin{array}{l}\text { With depression } \\
(N=116) \\
\text { S-BDI, } \geq 5\end{array}$}} & \multirow{2}{*}{\multicolumn{2}{|c|}{$\begin{array}{l}\text { No depression } \\
(N=660) \\
\text { S-BDI, } 0-4\end{array}$}} & \multirow{2}{*}{\multicolumn{2}{|c|}{$\begin{array}{l}\text { With depression } \\
(N=67) \\
\text { S-BDI, } \geq 5\end{array}$}} \\
\hline & & & & & & & & \\
\hline & $N$ & $\%$ & $N$ & $\%$ & $N$ & $\%$ & $N$ & $\%$ \\
\hline Do not want to tell anybody & 40 & 5.2 & 9 & 7.8 & 126 & 18.9 & 18 & 26.9 \\
\hline Have nobody to tell & 5 & 0.7 & 2 & 1.7 & 21 & 3.2 & 3 & 4.5 \\
\hline Friend(s)/peers/siblings & 326 & 42.3 & 60 & 51.7 & 149 & 22.4 & 20 & 29.8 \\
\hline Parent(s) & 65 & 8.4 & 6 & 5.2 & 111 & 16.7 & 6 & 9.0 \\
\hline Friend(s) or parent(s) & 331 & 43.0 & 39 & 33.6 & 252 & 37.8 & 19 & 28.3 \\
\hline Other (e.g. professionals) & 3 & 0.4 & 0 & 0.0 & 7 & 1.0 & 1 & 1.5 \\
\hline
\end{tabular}

${ }^{\text {a }}$ Data missing in one case.

${ }^{\mathrm{b}}$ Data missing in 34 cases.

atmosphere at home, poor relationship with mother and father, and parental divorce also associated with depression (Table 2).

At baseline, $7.8 \%$ of the females with subsequent depression and $5.2 \%$ of the other group reported not wanting to discuss their problems with anyone (Table 3). Half of those with subsequent depression had reported their personal problems only to age- mates, not to adults; none had contacted a professional as adolescents.

\subsection{Logistic regression analyses}

\subsubsection{Univariate associations}

In univariate logistic regressions (Table 4), the factors in mid-adolescence associating with subse-

Table 4

Odds ratios of predictor variables for depression at age 22 years for males, for females, for total population and interaction by gender

\begin{tabular}{|c|c|c|c|c|}
\hline & $\begin{array}{l}\text { Males } \\
\text { OR }(95 \% \text { CI })\end{array}$ & $\begin{array}{l}\text { Females } \\
\text { OR }(95 \% \text { CI })\end{array}$ & $\begin{array}{l}\text { Total population } \\
\text { OR }(95 \% \mathrm{CI})\end{array}$ & $\begin{array}{l}\text { Interaction } \\
P \text {-value }\end{array}$ \\
\hline Symptoms of depression & $4.89(2.7-8.8)$ & $2.40(1.5-3.9)$ & $3.26(2.2-4.7)$ & 0.065 \\
\hline Low self-esteem & $2.67(1.6-4.4)$ & $2.92(1.8-4.6)$ & $2.81(2.0-3.9)$ & 0.799 \\
\hline Low sense of individuation & $2.81(1.5-5.2)$ & $1.55(1.0-2.3)$ & $1.87(1.3-2.6)$ & 0.116 \\
\hline Poor perceived health & $2.27(1.2-4.3)$ & $1.21(0.7-2.1)$ & $1.57(1.0-2.4)$ & 0.152 \\
\hline Low mean of school marks & $2.02(1.2-3.5)$ & $1.4(0.9-2.1)$ & $1.60(1.2-2.2)$ & 0.274 \\
\hline \multicolumn{5}{|l|}{ Dissatisfied with academic } \\
\hline achievement & $1.71(1.0-2.8)$ & $2.13(1.4-3.2)$ & $1.95(1.4-2.7)$ & 0.495 \\
\hline Uncertain about future & $1.68(1.0-2.8)$ & $1.78(1.1-2.8)$ & $1.73(1.2-2.4)$ & 0.869 \\
\hline Excessive alcohol use & $1.01(0.6-1.8)$ & $1.0(0.6-1.6)$ & $1.0(0.6-1.5)$ & 0.961 \\
\hline Problems with the law & $3.61(1.8-7.1)$ & $1.9(0.6-6.0)$ & $3.0(1.7-5.4)$ & 0.352 \\
\hline Poor relationships with teachers & $1.66(0.9-3.2)$ & $1.83(1.0-3.3)$ & $1.75(1.1-2.7)$ & 0.832 \\
\hline Poor relationships with peers & $2.79(1.2-6.3)$ & $1.82(0.9-3.6)$ & $2.14(1.3-3.6)$ & 0.427 \\
\hline No close friends & $4.88(2.0-11.7)$ & $2.01(0.5-7.4)$ & $3.58(1.7-7.4)$ & 0.270 \\
\hline Not dating & $1.30(0.8-2.2)$ & $1.52(1.0-2.2)$ & $1.43(1.1-2.0)$ & 0.632 \\
\hline Interpersonal problems & $1.94(1.2-3.2)$ & $1.40(0.9-2.1)$ & $1.59(1.2-2.2)$ & 0.310 \\
\hline Life events & $1.48(0.9-2.4)$ & $1.42(1.0-2.1)$ & $1.44(1.1-2.0)$ & 0.905 \\
\hline Poor atmosphere at home & $3.35(1.9-6.0)$ & $1.84(1.2-2.8)$ & $2.30(1.6-3.3)$ & 0.109 \\
\hline Poor relationship with mother & $2.18(1.3-3.8)$ & $0.66(0.4-1.0)$ & $1.72(1.2-2.4)$ & 0.329 \\
\hline Poor relationship with father & $1.67(1.0-2.8)$ & $1.57(1.0-2.4)$ & $1.62(1.1-2.3)$ & 0.844 \\
\hline Parental divorce & $1.83(1.1-3.1)$ & $1.61(1.1-2.5)$ & $1.70(1.2-2.4)$ & 0.712 \\
\hline
\end{tabular}


quent depression only for the males were poor perceived health, low mean of school marks, problems with the law, poor relationships with peers, having no close friends, interpersonal problems and poor relationships with mother. Respectively, only for the females, poor relationships with teachers, not dating and life events associated with subsequent depression. The interaction models, however, showed no statistically significant evidence for gender differences in predictor variables (Table 4).

Interestingly, the OR for symptoms of depression among the males was higher than that among the females (interaction $P=0.07$ ). As can be seen in Tables 1 and 2, for both genders the scores of depressive symptoms among those with subsequent depression were equally high, although among the total female population the mean of depressive symptoms was higher than that among the male total population.

\subsubsection{Multivariate associations}

In multivariate analyses for both genders together symptoms of depression, as well as low self-esteem, dissatisfaction with academic achievement, problems with the law, poor atmosphere at home, and having no friends in mid-adolescence associated with subsequent depression at age 22 (Table 5).

In gender-specific multivariate analyses among the males, the statistically significant factors associating with depression at 22 years of age were: symptoms of depression at baseline, problems with the law, having no friends, and poor atmosphere at home (Table 5).
Respectively, among the females symptoms of depression at baseline, low self-esteem, and dissatisfaction with academic achievement associated with subsequent depression (Table 5).

\section{Discussion}

As hypothesized, symptoms of depression in midadolescence were a risk factor for later depression among both genders. Irrespective of methodological variations between studies, recent longitudinal research has shown that previous history of depression is a potential risk factor for depression (Lewinsohn et al., 1994; Frost et al., 1999). However, our prospective data on the antecedent impact of depressive symptoms are in line with those reporting that subclinical depression or depressive symptoms also predict subsequent depression among adolescents (Lewinsohn et al., 1988a; Ernst et al., 1992; Gotlib et al., 1995; Capaldi and Stoolmiller, 1999; Pine et al., 1999; Aalto-Setälä et al., in press). Previous research has reported different gender pathways in terms of risk trajectories (Allgood-Merten et al., 1990; Block et al., 1991; Ge et al., 1994; Frost et al., 1999). In our study, too, different factors arise for males and females as most important in gender specific multivariate analyses, though these differences were not statistically significant in interaction analyses.

Specific for the males, 'externalizing behavior' in terms of problems with the law at 16 years was a risk for subsequent depression. In line with these findings

Table 5

Summary of the stepwise logistic regression analyses: significant predictors with depression at age of 22 years, for males, for females and for total population

\begin{tabular}{|c|c|c|c|c|c|c|c|c|c|}
\hline & \multicolumn{3}{|c|}{ Males } & \multicolumn{3}{|c|}{ Females } & \multicolumn{3}{|c|}{ Total population } \\
\hline & OR & $(95 \% \mathrm{CI})$ & $P$-value & OR & $(95 \% \mathrm{CI})$ & $P$-value & OR & $(95 \% \mathrm{CI})$ & $P$-value \\
\hline Sex & - & - & - & - & - & - & 1.4 & $(1.0-1.9)$ & 0.089 \\
\hline Symptoms of depression & 3.4 & $(1.8-6.4)$ & $<0.0001$ & 2.0 & $(1.2-3.2)$ & 0.007 & 2.3 & $(1.5-3.4)$ & $<0.0001$ \\
\hline Low self-esteem & - & - & - & 2.3 & $(1.4-3.8)$ & 0.001 & 2.0 & $(1.4-2.9)$ & $<0.0001$ \\
\hline \multicolumn{10}{|l|}{ Dissatisfied with academic } \\
\hline Problems with the law & 3.0 & $(1.5-6.4)$ & 0.003 & - & - & - & 2.9 & $(1.6-5.4)$ & $<0.0001$ \\
\hline Poor atmosphere at home & 2.5 & $(1.3-4.7)$ & 0.007 & - & - & - & 1.5 & $(1.0-2.2)$ & 0.034 \\
\hline Having no friends & 2.9 & $(1.1-7.8)$ & 0.035 & - & - & - & 2.1 & $(1.0-4.5)$ & 0.067 \\
\hline Goodness-of-fit & \multicolumn{3}{|c|}{$\chi^{2}=2.4, \mathrm{df}=4, P=0.65$} & \multicolumn{3}{|c|}{$\chi^{2}=3.8, \mathrm{df}=5, P=0.57$} & \multicolumn{3}{|c|}{$\chi^{2}=5.7, \mathrm{df}=8, P=0.68$} \\
\hline
\end{tabular}


Capaldi and Stoolmiller (1999) reported that nonclinical males with depression and conduct problems in early adolescence continued to have depression in young adulthood. Also, in a longitudinal study by Block et al. (1991) males', but not females', conduct problems in pre-adolescence predicted dysthymia in late adolescence. However, Allgood-Merten et al. (1990) found in a 1-month follow-up no significant gender effect in antisocial tendencies for later depression.

The males with depression at 22 years had significant difficulties in their peer relationships during mid-adolescence. In accordance with these findings, Frost et al. (1999) reported that males' sense of poor social support from peers in mid-adolescence associated with depression in late adolescence. However, they also found that females' perception of being unpopular predicted later depression.

Poor atmosphere at home was another risk factor for males for subsequent depression. In agreement with these findings Frost et al. (1999) reported that frequent family arguments in mid-adolescence predicted later depression among males. However, low social support from parents (Lewinsohn et al., 1994) and parental difficulties (Reinherz et al., 1993) have been found significant predictors for subsequent depression also among females. In longitudinal studies the effect of family factors on the stability of problems has been weaker among adolescents than children (Ferdinand et al., 1995).

Low self-esteem in mid-adolescence, as expected, was a statistically significant predictor for subsequent depression. However, in gender-specific multivariate analyses, low self-esteem was a risk factor for subsequent depression only in females. Regardless of methodological disparities, low self-esteem is a wellknown correlate of depressive symptoms or disorders among females (Brown et al., 1986; Allgood-Merten et al., 1990; Reinherz et al., 1993). However, AllgoodMerten et al. (1990) found that low self-esteem was also predictive for later depression among males during a 1-month follow-up. On the other hand, low self-esteem did not predict subsequent depression in either gender in a prospective follow-up study by Ernst et al. (1992). The extent to which a variable's predictive ability diminishes as a function of time needs to be explored in future research. There seems to be something specific to the cognitive processing associated with adolescent depression. It is however, highly speculative to understand the co-occurrence of depression and self-esteem in adolescents: if low selfesteem is secondary to depression or vice versa. During the adolescent developmental process, selfconcept is developing and may be prone to, for example, previous loading life experiences and intrapsychic stress.

Also noteworthy was our finding that for the females, perceived poor academic achievement at 16 years was a significant predictor for subsequent depression. Previous research has mixed findings on the associations between academic difficulties and depression. In some studies dissatisfaction with grades predicted subsequent depression for both genders (Lewinsohn et al., 1994), whereas in others academic failure in pre-adolescence predicted depression in young adulthood among females (Reinherz et al., 1999) or both genders (Velez et al., 1989), but not in all studies (Offord et al., 1992).

Reportedly, depression in adolescence is underrecognized and undertreated (Keller et al., 1991). We found that more of those with subsequent depression reported not wanting to seek any help for their problems as adolescents. In accordance with the findings reviewed by Offer and Schonert-Reichel (1992), we found that females more often than males preferred friends when asked to whom they turned with their problems; few young people chose health care or other professionals.

\subsection{Methodological considerations}

Prospective, longitudinal research is essential in studying risk factors for depression (Frost et al., 1999). The strengths of this prospective study were a large representative 1 year age cohort comprising all 9th grade pupils from all social classes in a major Finnish city, and a 6-year follow-up. All shared the same language and ethnic background, and all had 9 years of education. The questionnaires were completed in class in a controlled and motivated environment; this also produced a very high response rate, and the questionnaire reports were found to be fairly reliable (Aro, 1987; Palosaari et al., 1996). Psychological problems were assumed to be more prevalent among dropouts, but the high response rate in both phases of the study enhanced the generalizability of the results. 
In this study we were interested in adolescents' subjective perceptions of their own well-being, behavior, and life situation. The self-report method gives valuable information on individual experiences during mid-adolescence. Although it may be problematic to thoroughly operationalize essential aspects of individuation and future orientation by means of questionnaires, these measures were fairly valid. We used many measures together, previously validated in earlier phases of the study. Nevertheless, the self-report method may carry the risk of underestimating use of alcohol and problems with the law, for example.

Although considerable continuity of problem behavior has generally been found (Hofstra et al., 2000), we do not know the possible effect of treatment on the course of problem behaviors from adolescence into young adulthood, the continuity of depression, or the number of depressive episodes in this population. According to a recent non-clinical population study, the recurrence of depression from mid-adolescence into young adulthood was 25\% (Hankin et al., 1998). Moreover, different risk factors for later depression reportedly exist for the first depression and for subsequent phases (Lewinsohn et al., 1994).

The measure of depression used at follow-up (SBDI) has proved a valid method among adolescents (Kaltiala-Heino et al., 1999). We had, however, no formal diagnosis of depression, and this self-report measure for screening depression does not necessary refer to depression of clinical severity. It has been suggested that the possibility of false positives using self-report measures of depression weakens the concordance between the self-report classification and the use of operational diagnostic criteria for depression (Lewinsohn et al., 1994). On the other hand, it has been reported that self-report measures substantially correlate with clinical diagnosis of depression among adolescents (Lewinsohn et al., 1988b). Unfortunately, in our study at baseline, depressed mood was not assessed although other symptoms of depression did. Notwithstanding our method of using a cluster of symptoms of depression at baseline, our results on the predictive impact of depressive symptoms were in line with those of Frost et al. (1999), who measured depression by questionnaire (CDI), by Pine et al. (1999), who used a modified interview schedule on depressive symptoms, and by Lewinsohn et al. (1994), who used structured diagnostic interviews (K-SADS).

\subsection{Conclusions}

Risk factors from several domains in mid-adolescence were associated with subsequent depression. Previously, adolescence was seen as a developmental period of severe emotional upheaval and turmoil, and constant conflicts with parents. Our findings are in line with recent studies indicating that young people prone to depression seem to suffer during adolescence from generalized psychosocial impairment and 'mood turbulence', assessed previously as being 'normal' (Offer and Schonert-Reichel, 1992; Ge et al., 1994; Lewinsohn et al., 1994; Champion et al., 1995; Hankin et al., 1998; Capaldi and Stoolmiller, 1999; Frost et al., 1999; Reinherz et al., 1999; Hofstra et al., 2000).

Our gender-specific analyses suggest that among the males the predictors for subsequent depression include in mid-adolescence symptoms of depression and more 'externalizing' factors (problems with the law, lack of peer contacts, stressful family environment), whereas among the females there are more 'internalizing' aspects (low sense of own worth, perceived school failure). Preventive efforts can be selectively targeted at adolescents who have been exposed to identifiable risk factors. Among depression-prone adolescents strengthening self-esteem, as well as improving academic achievement, seem to be essential. Our findings are likely to have implications for, e.g. social and health care services in detection and intervention with depression-prone youth having problems with the law. Early recognition and psychiatric treatment of depression are essential. It seems that efforts are needed to discover effective modes of psychosocial treatment (Harrington et al., 1998; Pelkonen et al., 1997), which would be accepted by adolescents with depression.

\section{Acknowledgements}

The study was financially supported by the Yrjö Jahnsson Foundation.

\section{References}

Aalto-Setälä, T., Marttunen, M., Tuulio-Henriksson, A., Poikolainen, K., Aro, H. Depressive symptoms in adolescence predict 
early adulthood depressive disorders and maladjustment. Am. J. Psychiatry, in press.

Allgood-Merten, B., Lewinsohn, P.M., Hops, H., 1990. Sex differences and adolescent depression. J. Abnorm. Psychol. 99, $55-63$.

American Psychiatric Association, 1994. Diagnostic and Statistical Manual of Mental Disorders, 4th Edition (DSM-IV). American Psychiatric Association, Washington, DC.

Aro, H., 1987. Life stress and psychosomatic symptoms among 14 to 16-year old Finnish adolescents. Psychol. Med. 17, 191-201.

Aro, H., 1988. Parental discord, divorce and adolescent development. Eur. Arch. Psychiatry Neurol. Sci. 237, 106-111.

Aro, H., 1994. Risk and protective factors in depression: a developmental perspective. Acta Psychiatr. Scand. Suppl. 89, 59-64.

Aro, H., Palosaari, U., 1992. Parental divorce, adolescence and transition to young adulthood. A follow-up study. Am. J. Orthopsychiatry $62,421-429$.

Aro, H., Rantanen, P., 1992. Parental loss and adolescent development. In: Chiland, C., Young, J.G. (Eds.), New approaches to mental health from birth to adolescence. V. The child in the family, Vol. 9. The Yearbook of the International Association for Child and Adolescent Psychiatry and Allied Professions. Yale University Press, New Haven, pp. 324-334.

Aro, H., Hänninen, V., Paronen, O., 1989. Social support, life events and psychosomatic symptoms among 14-16-year-old adolescents. Soc. Sci. Med. 29, 1051-1056.

Beck, A.T., Beck, R.W., 1972. Screening depressed patients in family practice. A rapid technique. Postgrad. Med. 52, 81-85.

Beck, A.T., Rial, W.Y., Rickels, K., 1974. Short form of depression inventory: cross-validation. Psychol. Rep. 34, 1184-1186.

Birmaher, B., Ryan, N.D., Williamson, D.E., Brent, D.A., Kaufman, J., Dahl, R.E., Perel, J., Nelson, B., 1996. Childhood and adolescent depression: A review of the past 10 years. Part I. J. Am. Child. Adolesc. Psychiatry 35, 1427-1439.

Block, J.H., Gjerde, P.F., Block, J.H., 1991. Personality antecedents of depressive tendencies in 18-year-olds: a prospective study. J. Pers. Soc. Psychol. 60, 726-738.

Brown, G.W., Harris, T.O., 1993. Aetiology of anxiety and depressive disorders in an inner-city population. 1. Early adversity. Psychol. Med. 23, 143-154.

Brown, G.W., Andrews, B., Harris, T., Adler, Z., Bridge, L., 1986. Social support, self-esteem and depression. Psychol. Med. 16, $813-831$.

Capaldi, D.M., Stoolmiller, M., 1999. Co-occurrence of conduct problems and depressive symptoms in early adolescent boys: III. Prediction to young-adult adjustment. Dev. Psychopathol. $11,59-84$.

Champion, L.A., Goodall, G., Rutter, M., 1995. Behaviour problems in childhood and stressors in early adult life. I. A 20 year follow-up of London school children. Psychol. Med. 25, 231-246.

Central Statistical Office of Finland, 1975. Classification of Occupations. Central Statistical Office, Helsinki, in Finnish.

Ernst, C., Schmid, G., Angst, J., 1992. The Zurich Study. XVI. Early antecedents of depression. A longitudinal prospective study on incidence in young adults. Eur. Arch. Psychiatry Clin. Neurosci. 242, 142-151.
Ferdinand, R.F., Verhulst, F.C., Wiznitzer, M., 1995. Continuity and change of self-reported problem behaviors from adolescence into young adulthood. J. Am. Acad. Child Adolesc. Psychiatry 34, 680-690.

Frost, A.K., Reinherz, H.Z., Pakiz-Camras, B., Giaconia, R.M., Lefkowitz, E.S., 1999. Risk factors for depressive symptoms in late adolescence: a longitudinal community study. Am. J. Orthopsychiatry $69,370-381$.

Ge, X., Lorenz, F.O., Conger, R.D., Elder, G.H., Simons, R.L., 1994. Trajectories of stressful life events and depressive symptoms during adolescence. Dev. Psychol. 30, 467-483.

Gotlib, I.H., Lewinsohn, P.M., Seeley, J.R., 1995. Symptoms versus a diagnosis of depression: Differences in psychosocial functioning. J. Consult. Clin. Psychol. 63, 90-100.

Hankin, B.L., Abramson, L.Y., Moffitt, T.E., Silva, P.A., McGee, R., Angell, K.E., 1998. Development of depression from preadolescence to young adulthood: emerging gender differences in a 10-year longitudinal study. J. Abnorm. Psychol. 107, $128-140$.

Harrington, R., Whittaker, J., Shoebridge, P., 1998. Psychological treatment of depression in children and adolescents. A review of treatment research. Br. J. Psychiatry 173, 291-298.

Hofstra, M.B., Van der Ende, J., Verhulst, F.C., 2000. Continuity and change of psychopathology from childhood into adulthood: a 14-year follow-up study. J. Am. Child Adolesc. Psychiatry 39, $850-858$.

Kaltiala-Heino, R., Rimpelä, M., Marttunen, M., Rimpelä, A., Rantanen, P., 1999. Bullying, depression and suicidal ideation in Finnish adolescents: school survey. Br. Med. J. 319, 348-351.

Keller, M.B., Lavori, P.W., Beardslee, W.R., Wunder, J., Ryan, N., 1991. Depression in children and adolescents: new data on 'undertreatment' and a literature review on the efficacy of available treatments. J. Affect. Disord. 21, 163-171.

Lewinsohn, P.M., Hoberman, H.M., Rosenhaum, M., 1988a. A prospective study of risk factors for unipolar depression. J. Abnorm. Psychol. 97, 251-264.

Lewinsohn, P.M., Hoberman, H., Teri, L., Hautzinger, M., 1988b. Adolescents depression: prevalence and psychosocial aspects. Paper presented at the Annual Meeting of the American Public Health Association, Boston, November 1988.

Lewinsohn, P.M., Roberts, R.E., Seeley, J.R., Rohde, P., Gotlib, I.H., Hops, H., 1994. Adolescent psychopathology: II. Psychosocial risk factors for depression. J. Abnorm. Psychol. $103,302-315$.

Lewinsohn, P.M., Gotlib, I.H., Seeley, J.R., 1995. Adolescent psychopathology: IV. Specificity of psychosocial risk factors for depression and substance abuse in older adolescents. J. Am. Acad. Child Adolesc. Psychiatry 34, 1221-1229.

Lewinsohn, P.M., Allen, N.B., Seeley, J.R., Gotlib, I.H., 1999. First onset versus recurrence of depression: differential processes of psychosocial risk. J. Abnorm. Psychol. 108, 483-489.

McGee, R., Feehan, M., Williams, S., Anderson, J., 1992. DSM-III disorders from age 11 to 15 years. J. Am. Acad. Child Adolesc. Psychiatry 31, 50-59.

Offer, D., Schonert-Reichel, K.A., 1992. Debunking the myths of adolescence: findings from recent research. J. Am. Acad. Child Adolesc. Psychiatry 31, 1003-1014. 
Offord, D.R., Boyle, M.H., Racine, Y.A., Fleming, J.E., Cadman, D.T., Blum, H.M., Byrne, C., Links, P.S., Lipman, E.L., MacMillan, H.L., Rae Grant, N.I., Sandford, M.N., Szatmari, P., Thomas, H., Woodward, C.A., 1992. Outcome, prognosis and risk in a longitudinal follow-up study. J. Am. Acad. Child Adolesc. Psychiatry 31, 916-923.

Palosaari, U., Aro, H., Laippala, P., 1996. Parental divorce and depression in young adulthood: adolescents' closeness to parents and self-esteem as mediating factor. Acta Psychiatr. Scand. 93, 20-26.

Pelkonen, M., Marttunen, M., Pulkkinen, E., Laippala, P., Aro, H., 1997. Characteristics of out-patient adolescents with suicidal tendencies. Acta Psychiatr. Scand. 95, 100-107.

Petersen, A.C., Compas, B.E., Brooks-Gunn, J., Stemmler, M., Ey, S., Grant, K.E., 1993. Depression in adolescence. Am. Psychol. 48, 155-168.

Pine, D.S., Cohen, E., Cohen, P., Brook, J., 1999. Adolescent depressive symptoms as predictors of adult depression: moodiness or mood disorder? Am. J. Psychiatry 156, 133-135.

Puig-Antich, J., Kaufman, J., Ryan, N.D., Williamson, D.E., Dahl, R.E., Lukens, E., Todak, G., Ambrosini, P., Rabinovich, H., Nelson, B., 1993. The psychosocial functioning and family environment of depressed adolescents. J. Am. Acad. Child Adolesc. Psychiatry 32, 244-253.
Reinherz, H.Z., Giaconia, R.M., Pakiz, B., Silverman, A.B., Frost, A.K., Lefkowitz, E.S., 1993. Psychosocial risks for major depression in late adolescence: a longitudinal community study. J. Am. Acad. Child Adolesc. Psychiatry 32, 1155-1163.

Reinherz, H.Z., Giaconia, R.M., Hauf, A.M.C., Wasserman, M.S., Silverman, A.B., 1999. Major depression in the transition to adulthood: risks and impairments. J. Abnorm. Psychol. 108, 500-510.

Renouf, A.G., Harter, S., 1990. Low self-worth and anger as components of the depressive experience in young adolescents. Dev. Psychopathol. 2, 293-310.

Rutter, M., 1989. Isle of Wight revisited: twenty-five years of child psychiatric epidemiology. J. Am. Acad. Child Adolesc. Psychiatry $28,633-653$.

Sugar, M., 1992. Late adolescent development and treatment. Adolesc. Psychiatry 18, 131-155.

Tulisalo, U.K., Aro, H.M., 2000. Parental remarriage as a modifier of proneness to depression in young adulthood. J. Affect. Disord. 57, 179-184.

Velez, C.N., Johnson, J., Cohen, P., 1989. A longitudinal analysis of selected risk factors for childhood psychopathology. J. Am. Acad. Child Adolesc. Psychiatry 28, 861-864. 